\title{
Getting to Know L2 Poor Comprehenders
}

\author{
Masoud Zoghi (Corresponding author) \\ Islamic Azad University - Ahar Branch, \\ Department of ELT, Faculty of Humanities \\ Km. 5 Ahar-Tabriz Road, Islamic Azad University Complex, Ahar, Iran \\ Tel: +984262232163Ｅ-mail: m-zoghi@iau-ahar.ac.ir \\ Ramlee Mustapha \\ Institute of Post-Graduate Studies \\ Sultan Idris Education University \\ 35900 Tanjong Malim, Perak, Malaysia \\ Tel: +6054505487Ｅ-mail: drrramlee@yahoo.com \\ Tengku Nor Rizan BT Tengku Mohamad Maasum \\ School of Language Studies and Linguistics \\ Faculty of Social Sciences and Humanities \\ Universiti Kebangsaan Malaysia, 43600 Bangi, Selangor, Malaysia \\ Tel: 603-8921-6475 E-mail: tntm@ukm.my
}

\begin{abstract}
Among the plethora of studies conducted thus far to explore the factors affecting EFL reading effectiveness, scant attention seems to be paid to the why of poor reading comprehension of most EFL learners. In this regard, the present article capitalized on qualitative research on a small scale, for the purpose of addressing the not-so-oftendebated issue of unsuccessful EFL reading competency in the Iranian context. In fact, the purpose of the article was to explore the degree of Iranian EFL learners' awareness of reading comprehension strategies and their potential comprehension failure. To this end, 12 EFL university-level students were interviewed, using a researcher-developed interview questionnaire. An analysis of student data interview revealed that there is an instructional void as regards to reading strategy training in the Iranian educational settings. Ultimately, based on the findings of the study, recommendations for future investigations are discussed.
\end{abstract}

Keywords: Cognitive view to reading, Reading comprehension, Poor comprehension, Reading strategies

\section{Introduction}

Reading, whether in first language (L1) or second/foreign language (L2), has drawn a considerable degree of pro and con debates among experts over its interpretation during the past forty years. It has been conceptualized and defined in numerous ways; however, the areas of commonality outweigh the differences. In the meantime, so much attention has also been directed toward comprehension in reading now and in years past. There is a general consensus of opinions concerning the definition that views reading comprehension as the process of unlocking meaning from connected text. However, the probing of the relevant literature encourages one to infer that less attention has been devoted in empirical investigations carried out to date on poor comprehension of EFL learners. In this connection, this writing thrived to re-raise the issue of L2 poor comprehension. Overall, the present paper explored the notion that the reason why some EFL readers excel and others struggle lies in what they themselves do - the strategies that they bring to L2 reading. As an initial step, we posited our discussions on a theoretical perspective to reading. The following section will deal with this particular perspective.

\subsection{Cognitive View to Reading}

As a way of drawing on the potentially overwhelming available information, in this article attempts have been made to adhere to a specific perspective on reading among many others i.e. the cognitive view. Although there are a number of other theoretical stances that this study can capitalize on, the selection of this particular perspective to reading for this writing should not imply that the authors are of the opinion that it is the most comprehensive view, rather it can be seen as a reading theory that has potential utility in guiding reading intervention research (Deshler \& 
Hock, 2007).

The governing contention in this postulation is that reading is an interaction between reader and text, which can be further segmented into different levels, all of which happen concurrently. On a broader note, such an interaction first begins with the 'decoding' of linguistic information from print. Then, in the 'text-information building' phase, ideas extracted during reading are combined to unlock text meanings. Eventually, in 'situation-model construction', the information obtained is synthesized with prior knowledge. Put differently, according to this perspective, reading comprehension takes place at (a) the word level, (b) the level of proposition, (c) the level of local coherence, (d) the level of macrostructure of the text, and (e) the level of superstructure including the context of the reading event (Carpenter, Miyake \& Just, 1994; Kintsch, 1998; Miller, 1988; Perfetti, 1994).

It should be noted that even though this postulation aims at L1 readers, it does have some parallels with L2 reading, since the essential reading competency factors in general are similar in L1 and L2 reading (Eskey 2005). Although meager in size, some understandings gained from L1 reading comprehension processes have already begun to penetrate into L2 reading over the last 30 years. And, researchers in the L2 reading research community have confirmed the interactivity of reading processes proposed in the cognitive view (Erler \& Finkeiner, 2007).

As stated above, in light of the cognitive view to reading, reading comprehension is sequential, namely it is composed of a series of stages, "each of which is complete before the next stage begins" (Urquhart \& Weir, 1998, p. 39). Overall, decoding skills in this view, "account for a moderate, but significant portion of L2 reading variance" (Koda, 2005, p.25). In point of fact, reading comprehension cannot occur effectively unless decoding skills have been mastered. However, skill in decoding or possessing linguistic knowledge does not necessarily imply skill in reading comprehension (Eskey, 2005; Perfetti, 1988).

Based on the cognitive view to reading, it is often argued that many L2 readers decode texts quite readily but still have difficulty understanding what it is that they have decoded (Yuill \& Oakhill, 1991). Put differently, some L2 readers seem to be able to reach the first stage of the cognitive view, but they may not succeed in proceeding any further, and consequently encounter comprehension breakdowns. Bernhardt (1991) holds that such readers seem to be able to identify the 'seen' elements of the text (e.g. word meaning or syntax), but they suffer from lack of operational knowledge: knowing how to approach text, knowing why they approach it, and what to do with it.

The importance of cognitive processing skills were noted by such reading experts more than 40 years ago as Miller (1965) and Cromer (1968), arguing that the meaning of a sentence is not a linear sum of the meanings of the words that comprise it. The 1968 Cromer study provided a useful conceptualization of the reading comprehension problem. He identified two groups of poor readers: 'the deficit group' and 'the difference group'. The deficit poor readers, according to his classification, do not comprehend because of a failure in decoding skills to extract the meanings of individual words. The difference poor readers, on the other hand, do have decoding skills, but they do not adequately comprehend sentence or passage meaning. Further support for this conceptualization of poor readers is found in Cain, Oakhill, Barnes, and Bryant (2001); Isakson and Miller (1976); Nation, Clarke, Marshall, and Durand (2004).

On the basis of cognitive view, it is evident that successful comprehension depends on two key factors: linguistic knowledge and the skills to put the knowledge for text-meaning construction into use (Koda, 2005). While it must be acknowledged that reading comprehension is such a complex process that can fail for a host of possible reasons, and besides, no clear 'poor comprehender's profile has emerged yet (Nation et al., 2004), a growing body of research has identified a certain type of poor comprehenders as a group of readers who have the ability to decode and associate meaning with single words, but they fail to integrate the meanings of separate words to arrive at the meaning of an entire sentence or of the whole text (Wise, 1999). Presumably, such ideas have motivated Stahl and Nagy (2006, p. 10) to claim that "the knowledge of individual words is simply the tip of the iceberg -- it is the rich, interconnected knowledge of concepts that really drives comprehension".

With regard to the theoretical perspective stated above and, also, in order to probe into the ideas expressed in the literature, the present study set out to seek an appropriate answer to the following question as far as the scope of this article permitted: To what extent can poor comprehension of EFL learners be put down to a lack of reading strategies knowledge?

\section{Methodology}

A qualitative research design was used to address the formulated research question of this study since qualitative research uses a naturalistic approach that seeks to understand phenomena in context-specific settings, such as "real world setting [where] the researcher does not attempt to manipulate the phenomenon of interest" (Patton, 2002, p. 39). To this end, data was collected from semi-structured interviews. What is more, to ensure 'trustworthiness' of the data, three concerns related to qualitative research methodology were taken into account: transferability, 
dependability and confirmability (Mackey \& Gass, 2005). In terms of transferability, a specific method of reporting known as 'thick description' was used. In fact, findings were reported in detail. Specifically, certain representative examples from the data were utilized and information about the patterns in the data was provided. To increase dependability, the first author himself asked the participants to review the patterns emerged from the qualitative data. Finally, for confirmability, attempts were made to make available full details of the data on which researchers were basing their interpretations.

\subsection{Participants}

The participants of this study consisted of 12 university-level seniors majoring in TEFL in a university located in the eastern Azarbaijan province of Iran. Students were selected after obtaining verbal consent from the academic administration office of the university. Since only this student population $(\mathrm{N}=34)$ in the selected university expressed their consent to participate in the study, the sample $(n=12)$ was randomly taken from this particular population. Moreover, because in qualitative studies "researchers tend to work more intensively with fewer participants, ..." (Mackey \& Gass, 2005, p. 163), the number of participants in the current research was not considered a matter of considerable concern. At the time of conducting the study, i.e. in the academic year of 2007-2008, all the participating students were studying the TEFL program offered by the Faculty of Humanities. Of the 12 participants, 58.3 per cent were males $(n=7)$, with a mean age of 24 years, and 41.7 per cent females $(n=5)$ with a mean age of 20 years.

\subsection{Instrument}

To collect the intended qualitative information, an interview questionnaire was developed. It consisted of open-ended questions which aimed at eliciting information about the participating students' experience regarding reading strategies instruction. In this semi-structure interview, a written list of questions was prepared in order to allow for the possibility of comparing answers from different respondents. The interviews were conducted in respondents' L1, so that concerns regarding the proficiency of learners affecting the quality and quantity of the data could be removed (Mackey \& Gass, 2005). The interview questionnaire comprised five open-ended questions in L1 (see below for the English version of the questions) which primarily focused on probing into the students' perceptions about reading strategies instruction. They are as follows:

Q\#1 What are the problems that you encounter while reading L2 texts?

Q\#2 How do you try to overcome those problems?

Q\#3 What aspect of language is emphasized in your reading classes?

Q\#4 Has your reading instructor ever taught reading strategies? (Name a few)

Q\#5 Have they been useful in your subsequent readings? (Probe)

\subsection{Procedures}

The interview sessions were conducted by the researcher. Each interview lasted approximately 10-15 minutes during which the responses from the interviewees were taped-recorded. The respondents were randomly selected as they expressed their consent to participate in the interview. Once the permission was given by the respondents, their answers were tape-recorded, and after the transcription they were erased. Once the qualitative data analysis was completed, the participants were asked to examine the patterns obtained in the data.

\section{Results}

The interview tape was transcribed, noting not only the literal statements, but also non-verbal and paralinguistic communication. Once the verbatim transcripts were prepared, the researcher subjected the data to content analysis by means of coding them. In fact, coding procedures of the interview data were based on open coding (theme identification) and axial coding proposed by Strauss \& Corbin (1998). According to Strauss \& Corbin (1998, p. 61) open coding involves "the process of breaking down, examining, comparing, conceptualizing, and categorizing data". During open coding, entire interviews were read and reread so that patterns and major themes in the data could be identified. After that, the data was categorized around the themes.

Axial coding, as Strauss \& Corbin (1998) explicate, involves a set of procedures through which data is put back together in new ways after open coding, by making connections between a category and its sub-categories. During axial coding, the identified categories were refined and narrowed down with regard to sub-categories. Further, the data was re-categorized around the refined/narrowed themes.

Upon completion of the data coding, many similarities and a couple of differences emerged in the ways respondents reported their experiences about reading strategies instruction. In effect, analysis of students' interview data generated four major themes: (a) overall problems encountered during reading L2 texts, (b) ways of solving 
comprehension problems, (c) primary focus of reading classes, and (d) attitudes toward strategy instruction and its usefulness. In the subsequent sub-section where the data interpretation will be dealt with, evidence to support the findings is provided by using original, key quotations from the respondents. To ensure that students stay anonymous, respondents received an alphabet letter.

(a) Overall problems encountered during reading L2 texts

When asked about their problems that they usually undergo when they read texts in English, most of the students except three referred to 'above-the-word-level comprehension difficulties', for which they had the slightest idea of how to overcome. Some examples of their common reading problems were reported as follows:

"Perhaps, my big problem is that I can't see how and why the ideas in the text are interconnected" (STUDENT C).

"I know the meaning of most words. I kind of think I have developed good vocabulary knowledge in English; however, I can't really put back pieces of information together" (STUDENT G).

"My main problem is that I am not able to extract main ideas from a paragraph. So, I can't, sometimes of course, establish any relationship between sentences" (STUDENT A).

Three of the respondents attributed their reading problems to their limited vocabulary knowledge, as noted in the following comments:

"Admittedly, my vocabulary is not that big. So, it really bugs me when I don't know the meaning of a word" (STUDENT H).

"I guess I have not learned enough English vocabularies. And, Uh, my vocabulary is limited; so, I face a lot of problems during reading" (STUDENT B).

"Well, some of the words in English look like I have never seen them before. They are really difficult and I can't seem to find any equivalent in Persian for them" (STUDENT J).

(b) Ways of solving comprehension problems

In addition to examining the problems that students face while reading L2 texts, their personal strategies in dealing with such problems were also investigated. Unsurprisingly, they did not have a clear idea of how to take compensatory actions when they encounter comprehension breakdowns. For instance, one student openly stated that

"I realy don't know what to do then. To tell you the truth, I guess something is wrong with my memory [laughing]" (STUDENT I).

Another student gave a rather convincing response and said that

"I usually underline or highlight the main points. But, it doesn't seem to work all the time. I soon get confused by differing bits of information in the text" (STUDENT D).

Some, however, reported a meager use of reading strategies in dealing with unfamiliar vocabulary items, as noted in the following comments:

"I sometimes use my dictionary or try to guess the meaning of the unknown word" (STUDENT F).

"Breaking down the unknown word into pieces is often effective...even finding about its part of speech is helpful" (STUDENT K).

(c) Primary focus of reading classes

Interestingly, an analysis of the student interview data revealed that the primary focus of attention in most of their EFL reading classes was directed on translation activities. The majority of the students stressed that class activities basically concentrated on translating different parts of an L2 text into L1. For instance, a couple of them mentioned that

"Most of the time we used to have translation activities. The instructor had us find Farsi equivalents of unfamiliar words" (STUDENT C).

"Either the instructor or one of us [students] would translate the reading from English into Farsi" (STUDENT H).

"Our instructor would ask us write the Farsi equivalents of unknown words on the margin of the page. Then, Uh, we had to come up with our own translation" (STUDENT A).

Reading comprehension questions generated by the reading instructors was another feature that was viewed as an integral part of their reading classes. Several of the students asserted that

"We were asked to answer the questions once the reading-aloud of the material was over" (STUDENT F). 
"At the end of the sessions, students had to find answers to the questions that the instructor came up with" (STUDENT E).

Only one student indicated that the primary focus of attention in her classes was on post-reading activities such as discussion. She pointed out that

"Once the instructor ensured we understood the message of the text, he or she used to conduct debates in L2, for the purpose of improving our speaking abilities" (STUDENT L).

(d) Attitudes toward strategy instruction and its usefulness

Finally, students were asked about their reading strategy training that they had received to date. The students' responses were quite similar with regard to their experience with the term 'reading strategies'. In effect, their responses revealed that students had not had a systematic strategy instruction in their reading classes.

"A few of them [reading strategies] were taught in our reading classes...for example scanning or skimming" (STUDENT K).

"The reading strategies taught in our reading classes, of course the ones that I can think of offhand, were how to differentiate main ideas from minor ideas or how to differentiate facts from opinions (STUDENT D).

"Our instructor taught us a couple of reading strategies. Uh, I can't remember them exactly, but I guess they were strategies like making inferences, and identifying main ideas and supporting details" (STUDENT F).

Surprisingly, the term 'reading strategies' was foreign to some of the respondents, as noted in the following comments:

"I don't know what you mean by 'reading strategies', but we, uh, were always told to use a monolingual dictionary and to also translate sentence by sentence rather than word by word" (STUDENT G).

"Would you please give some clarification on 'reading strategies'? What do they refer to? I don't think I have any idea about them" (STUDENT J).

In addition, students ' attitudes toward the usefulness of reading strategies was also investigated. None of the respondents, however, asserted that reading strategies were effective in their later readings. The reason for such a way of thinking could be sought in the fact that students had never been taught about the what, why, and how of reading strategies in a systematic fashion. Some of their direct quotes were:

"No, they never have" (STUDENT K).

"No. Because when I read texts in English, I don't think about those things" (STUDENT G).

"I don't think they have" (STUDENT H).

"I don't have any idea" (STUDENT B).

\section{Discussion}

The outcomes of this study seem to give the resounding answer 'To a great extent' to the research question formulated at the outset of this study: To what extent can poor comprehension of EFL learners be put down to a lack of reading strategies knowledge? It can be stated that poor comprehenders' short circuits [a term coined by Goodman (2003) implying reading without meaning] can be attributed to their text processing characteristics which is, in turn, due to their deficiency in strategic reading and monitoring their understanding of the material read.

Findings also reveal a pedagogical gap that exists in some academic settings in Iran i.e. the need to focus attention on developing strategic reading behaviors in EFL learners. A number of studies conducted by Varzegar $(1995,1997$, 2001) show that most Iranian EFL learners are slow and word-by-word readers i.e. they do not read in "holistic chunks" and if they do, those chunks are arbitrary. It is generally reported that such learners are restricted to a responding role because of the system of education focusing on rote-memorization and Grammar-Translation Method. As a result, they are typically able "to decode the message" (i.e. understand the meaning of a word, phrase, or sentence) with the help of a dictionary; however, they are unable to "demessage" it, namely they fail to reach the scriptual, schematic and pragmatic levels of comprehension (Varzegar, 1995, p. 112).

Findings of the current research comport with several empirical research studies that have also underlined the idea that an important bottleneck in reading comprehension occurs at the discourse level (Cain \& Oakhill, 1998). That means that poor comprehenders apparently fail to integrate ideas activated at sentence-level to achieve global text coherence (Catts, Adlof, \& Weismer, 2006; Long \& Chong, 2001). It follows from the foregoing that reading comprehension difficulties of this group of poor comprehenders are attributable to 'above-the-word-level comprehension processes', which can be, in the main, considered as reading-based comprehension problems, rather 
than language-based comprehension difficulties.

\subsection{Limitations}

Several limitations influence the interpretation of this study. Although it is argued that reliability and validity of data sources in qualitative research paradigm plays a minor role (Creswell, 2003), 'trustworthiness' of the interview data in this study can be cause for concern and needs to have been specified. Perhaps, for the validation process, a common procedure could have been the triangulation of data sources by incorporating an additional measure such as a reading strategies questionnaire. Likewise, peer-checking and member-checking, as they are maintained, would have been a strategy of choice for determining reliability of qualitative data. This speaks to the need for further extensive investigations. Moreover, accommodation of instructors' perceptions regarding reading strategies instruction in this research could have potentially complemented and enriched the outcomes of the study. Clearly, this warrants further explorations in this regard.

\section{Conclusion}

Overall, empirical research results show that reading comprehension does not develop once word decoding and meaning association are proficient, but that it is dependent on different skills and may need specific teaching (Oakhill \& Cain, 2000). "Linguistic knowledge and its processing skills" as Koda (2005, p. 10) observes, "do not, of necessity, develop concomitantly". Therefore, we suggest that, in the Iranian context, reading experts should treat reading and strategic reading as totally different notions, and devise procedures in the form of instructional practices in a way that L2 unaccomplished readers could be assisted to develop strategies of reading independently. Thus, tailoring effective strategy instruction, in our judgment, would enable such poor comprehenders to develop the skills necessary to construct integrated and coherent representation of texts. Put differently, by providing L2 poor comprehenders with a set of evidence-based reading strategies designed to help synthesize meaning in larger segments of text, their strategic reading behavior could be enhanced. Thus, instruction for poor comprehenders should include a bridging strategy that provides explicit strategy instruction and scaffolded support to help them overcome their fragile understanding of text read.

In this regard, adequate attention should be paid to what reading strategies should be taught and how and where instruction should occur. As learning is context-dependent i.e. it cannot be divorced from the situation in which it occurs, it makes sense, therefore, to look into our classrooms and examine what instructional practices improve the reading performance of EFL learners as we seek to implement research-derived interventions. In sum, future empirical research could reveal that whether or not, in a specific context, a certain reading program enhanced with effective reading comprehension strategies could help poor comprehenders combat their comprehension failure.

\section{References}

Bernhardt, E. B. (1991). Reading Development in a Second Language. Norwood, NJ: Ablex.

Cain, K., \& Oakhill, J. V. (1998). Comprehension skill and inference-making ability: Issues of causality. In C. Hulme \& R.M. Joshi (Eds.). Reading and Spelling. Mahwah, NJ: Lawrence Erlbaum Associates, Inc.

Cain, K., Oakhill, J. V., Barnes, M. A., \& Bryant, P. E. (2001). Comprehension skill, inference making ability, and their relation to knowledge. Memory \& Cognition, 29, pp.850-859.

Carpenter, P. A., Miyake, A., \& Just, M. A. (1994). Working memory constraints in comprehension: Evidence from individual differences, aphasia, and aging. In M. A. Gernsbacher (Ed.) Handbook of Psycholinguistics. New York: Academic Press.

Catts, H. W., Adlof, S. M., \& Weismer, S. E. (2006). Language deficits in poor comprehenders: A case for the simple view of reading. Journal of Speech, Language, and Hearing. 49 (2), pp.278-294.

Creswell, J. W. (2003). Research design: Qualitative, quantitative, and mixed methods approaches. Thousand Oaks, Ca.: Sage Publications.

Cromer, W. (1968). The effects of preorganizing reading material on two types of poor readers. Unpublished doctoral dissertation, Clark University.

Deshler, D. D., \& Hock, M. F. (2007). Adolescent literacy: Where we are, where we need to go. In M. Pressley, A. K. Billman, K. H. Perry, K. Reffitt, \& J. M. Reymonds (Eds.), Shaping literacy achievement: Research we have, research we need. New York: Guildford.

Erler, L. \& Finkeiner, C. (2007). A review of reading strategies: Focus on the impact of first language. In A. D. 
Cohen, and E. Macaro (Eds.), Language learner strategies (2nd ed). Oxford: Oxford University Press.

Eskey, D. E. (2005). Reading in a Second Language. In E. Hinkel (ED.), Handbook of research in second language teaching and learning. Mahwah, NJ: Lawrence Erlbaum Associates, Inc.

Goodman, K. S. (1967). Reading: A psycholinguistic guessing game. Journal of the Reading Specialist 6, pp.126-135.

Goodman, K. S. (2003). Unity in reading. In A. D. Flurkey \& J. Xu (Eds.), On the revolution of reading: The selected writings of Kenneth $S$. Goodman. Portsmouth, NH : Heinemann.

Isakson, R. L., \& Miller, J.W. (1976). Sensitivity to syntactic and semantic cues in good and poor comprehenders. Journal of Educational Psychology 8 (6), pp.787-792.

Kintsch, W. (1998). Comprehension: A paradigm for cognition. New York: CPU.

Koda, K. (1993). Transferred L1 strategies and L2 syntactic structure during L2 sentence comprehension. Modern Language Journal. 77, pp.490-500.

Koda, K. (2005). Insights into second language reading: A crosslinguistic approach. Cambridge: Cambridge University Press.

Long, D. L., \& Chong, J. L. (2001). Comprehension skill and global coherence: A paradoxical picture of poor comprehenders' abilities. Journal of Experimental Psychology: Learning, Memeory, and Cognition. 27 (6), pp.1424-1429.

Macaro, E. (2003). Teaching and learning a second language: A review of recent research. London: Continuum.

Miller, G. A. (1965). Some preliminaries to psycholinguistics. American Psychologist, 20, pp.15-20.

Miller, G. A. (1988). The challenge of universal literary. Science, 241, 1293-1299.

Nation, K., Clarke, P., Marshall, C. M., \& Durand, M. (2004). Hidden language impairments in Children: Parallels between poor reading comprehension and specific language impairment?. Journal of Speech, Language, and Hearing. 47 (1), pp.199-212.

Oakhill, J., \& Cain, K. (2000). Children's difficulties in text comprehension: Assessing causal issues. Journal of Deaf Studies and Deaf Education, 5 (1), pp.51-59.

Patton, M. Q. (2002). Qualitative evaluation and research methods (3rd Ed.). Thousand Oaks, CA: Sage Publications, Inc.

Perfetti, C. A. (1994). Psycholinguistics and reading ability. In M. A. Gernsbacher (Ed.) Handbook of Psycholinguistics. New York: Academic Press.

Pressley, M. (2002). Metacognition and self-regulated comprehension. In Farstrup, A. E. \& Samuels, S. J. (Eds.). What research has to say about reading instruction. San Francisco,CA: Josset-Bass.

Stahl, S. A., \& Nagy, W. E. (2006). Teaching word meanings. Mahwah, N.J. : L. Erlbaum Associates.

Strauss, A., \& Corbin, J. (1990). Basics of qualitative Research: Grounded theory procedures and techniques. Newbury Park, CA: Sage Publications, Inc.

Urquhart, A. H. \& Weir, C. J. (1998). Reading in a second language: Process, product, and practice. London: Longman.

Varzegar, M. (1995). The discoursal aspects of reading comprehension. Pazhuhesh, 11, pp.109-120.

Varzegar, M. (1997) The Impact of extroversion-introversion on EFL reading comprehension. Tehran: Journal of the College of Foreign Languages.

Varzegar, M. (2001). Academic competence and teaching reading. Paper Presented at International Reading Associaition Convention. New Orleans.

Wise, B. (1999). The promise and limits of phonological training for children with specific reading disabilities. ASHA Division 1: Language, Learning, \& Education Newsletter, 6, pp.22-24.

Yuill, N. M. \& Oakhill, J. V. (1991). Children's problems in text comprehension: An experimental investigation. Cambridge: Cambridge University Press. 